Published on Web 11/19/2004

\title{
Oriented Attachment and Membrane Reconstitution of His-Tagged Cytochrome $c$ Oxidase to a Gold Electrode: In Situ Monitoring by Surface-Enhanced Infrared Absorption Spectroscopy
}

\author{
Kenichi Ataka, ${ }^{\dagger}$ Frank Giess, ${ }^{\ddagger}$ Wolfgang Knoll, ${ }^{\ddagger}$ Renate Naumann, ${ }^{\ddagger}$ \\ Sabina Haber-Pohlmeier, ${ }^{\dagger}$ Björn Richter ${ }^{\dagger}$ and Joachim Heberle ${ }^{*, \dagger}$ \\ Contribution from the Forschungszentrum Jülich, IBI-2: Structural Biology, Jülich, Germany, \\ and Max-Plank Institute for Polymer Research, Mainz, Germany \\ Received July 7, 2004; E-mail: j.heberle@fz-juelich.de
}

\begin{abstract}
A novel concept is introduced for the oriented incorporation of membrane proteins into solid supported lipid bilayers. Recombinant cytochrome $c$ oxidase solubilized in detergent was immobilized on a chemically modified gold surface via the affinity of its histidine-tag to a nickel-chelating nitrilo-triacetic acid (NTA) surface. The oriented protein monolayer was reconstituted into the lipid environment by detergent substitution. The individual steps of the surface modification, including (1) chemical modification of the gold support, (2) adsorption of the protein, and (3) reconstitution of the lipid bilayer, were followed in situ by means of surface-enhanced infrared absorption spectroscopy (SEIRAS) and accompanied by normalmode analysis. The high surface sensitivity of SEIRAS allows for the identification of each chemical reaction process within the monolayer at the molecular level. Finally, full functionality of the surface-tethered cytochrome $c$ oxidase was demonstrated by cyclic voltammetry after binding of the natural electron donor cytochrome $c$.
\end{abstract}

\section{Introduction}

Membrane proteins play a central role in the physiology of living cells and fulfill a number of important functions, for example, energy metabolism, cell-cell interaction, or uptake of nutrients and ions. In fact, many hereditary and acquired diseases are attributed to defects in the functionality of membrane proteins. Despite their importance, the structurefunction relation of many membrane proteins is not fully understood because of the complexity of the structure and the intricacy of the molecular reactions.

Monolayers of proteins employ a solid support with which the functional properties of the tethered proteins can be conveniently controlled. The design of such biofunctional surfaces is a major topic in contemporary nanobiotechnology. ${ }^{1}$ It is the goal to immobilize proteins under preservation of their structural integrity and functionality. The chemically modified electrode (CME) approach has achieved great success on the immobilization of several water soluble proteins. ${ }^{2}$ However, the application of this methodology to membrane proteins is still difficult. $^{3}$

An experimental challenge is the sensitivity of membrane proteins to degeneration as soon as they are removed from the native lipid bilayer and solubilized with the help of detergents.

\footnotetext{
$\dagger$ Forschungszentrum Jülich.

$\doteqdot$ Max-Plank Institute for Polymer Research

(1) Willner, I.; Katz, E. Angew. Chem., Int. Ed. 2000, 39, 1180-1218.

(2) Jeuken, L. J. C. Biochim. Biophys. Acta 2003, 1604, 67-76.

(3) Guidelli, R.; Aloisi, G.; Becucci, L.; Dolfi, A.; Moncelli, M. R.; Buoninsegni, F. T. J. Electroanal. Chem. 2001, 504, 1-28.

10.1021/ja045951h CCC: $\$ 27.50$ @ 2004 American Chemical Society
}

To mimic the native lipid environment, solubilized membrane proteins are re-integrated (reconstituted) in artificial lipid bilayers or lipid analogues. Several reconstitution strategies on solid supports have been applied, ${ }^{4}$ such as the insertion into hybrid lipid bilayer membranes of self-assembled monolayers of alkane thiols and phospholipids, ${ }^{4}$ tethered lipid bilayer membranes (tBLMs), ${ }^{5,6}$ polymer membranes, ${ }^{7}$ and Langmuir-Blodgett films. ${ }^{8}$ With all of these techniques, it is extremely difficult to control the orientation as well as the surface concentration, which is crucial for the analysis of its function.

To overcome these obstacles, we have developed a novel methodology for surface reconstitution of membrane proteins. ${ }^{9}$ This novel approach combines two common experimental concepts. First, the metal surface is modified by attaching a nitrilotriacetic (NTA) moiety to the metal via a sulfhydryl group at the other end. After complex formation with $\mathrm{Ni}^{2+}$, a recombinant membrane protein engineered to bear a stretch of six consecutive histidine residues at the $\mathrm{C}$ - or the $\mathrm{N}$-terminus is attached by the affinity to the Ni-NTA moiety. This concept

(4) Burgess, J. D.; Rhoten, M. C.; Hawkridge, F. M. Langmuir 1998, 14, $2467-$ 2475 .

(5) Naumann, R.; Schmidt, E. K.; Jonczyk, A.; Fendler, K.; Kadenbach, B.; Liebermann, T.; Offenhausser, A.; Knoll, W. Biosens. Bioelectron. 1999 $14,651-662$.

(6) Schmidt, E. K.; Liebermann, T.; Kreiter, M.; Jonczyk, A.; Naumann, R.; Offenhausser, A.; Neumann, E.; Kukol, A.; Maelicke, A.; Knoll, W. Biosens. Bioelectron. 1998, 13, 585-591.

(7) Hara, M.; Asada, Y.; Miyake, J. Mater. Sci. Eng., C 1997, 4, 321-325.

(8) Yasuda, Y.; Kawakami, Y.; Toyotama, H. Thin Solid Films 1997, 292, 189-191.

(9) Giess, F.; Friedrich, M.; Heberle, J.; Naumann, R.; Knoll, W. Biophys. J. 2004, 87, 3213-3220.

J. AM. CHEM. SOC. 2004, 126, 16199-16206

16199 
is well-known from metal ion affinity chromatography ${ }^{10}$ and has already been employed to selectively attach proteins to metal surfaces. ${ }^{11-17}$ Second, the oriented, surface-attached, and detergent-solubilized protein is reconstituted in a lipid environment by in situ dialysis. ${ }^{9}$ In situ dialysis has been employed before, ${ }^{4,17,18}$ however, it was not combined with the oriented attachment of the protein. The combined concept ensures both the oriented immobilization and the restoration into a physiologically natural matrix that enhances the stability of the membrane protein and preserves its functionality.

Besides the surface design of the membrane protein monolayer, a serious experimental predicament is the structural assessment of such a layer. Basic requirements for the characterization comprise: (1) High surface sensitivity and selectivity to detect monolayer amounts of the sample (in the order of pmol/ $\mathrm{cm}^{2}$ ) without contributions from material in the bulk medium, (2) measurements are performed under in situ conditions, that is, in aqueous media to preserve the integrity of the protein monolayer, and (3) a favorable technique would provide information on the molecular or even atomic level. Infrared spectroscopy can fulfill all of these requirements when surfaceenhanced infrared absorption spectroscopy (SEIRAS) is employed. There, the noble metal surface exhibits a strong electromagnetic field that leads to the enhancement of vibrational transitions of bound molecules. The enhancement decays rapidly with the distance from the surface $(<8 \mathrm{~nm})$, which eliminates the bulk contribution to the IR spectrum and selectively detects signals from the adsorbed monolayer even when the surface is immersed in water. ${ }^{19-24}$

In this work, we employ SEIRAS to demonstrate the successful reconstitution of an oriented monolayer of cytochrome $c$ oxidase $(\mathrm{CcO})$ into a lipid bilayer along the solid surface of gold. SEIRAS, which exploits the surface enhancement, monitors each single step of the surface modification in situ. The assignment of the observed vibrational bands related to the each surface reaction step has been performed by quantum mechanical calculations. We used recombinant $\mathrm{CcO}$ from the proteobacterium Rhodobacter sphaeroides with a His-tag engineered into the $\mathrm{C}$-terminus of subunit I that orients the $\mathrm{CcO}$ to have the cyt $c$ binding site freely accessible to the aqueous bulk phase. Previous work on $\mathrm{CcO}$ adhered to a gold

(10) Goldsmith, J. O.; Boxer, S. G. Biochim. Biophys. Acta 1996, 1276, 171175.

(11) Kröger, D.; Liley, M.; Schiweck, W.; Skerra, A.; Vogel, H. Biosens. Bioelectron. 1999, 14, 155-161

(12) Liley, M.; Keller, T. A.; Duschl, C.; Vogel, H. Langmuir 1997, 13, 41904192.

(13) Nakamura, C.; Hasegawa, M.; Nakamura, N.; Miyake, J. Biosens. Bioelectron. 2003, 18, 599-603.

(14) Rigler, P.; Ulrich, W. P.; Hoffmann, P.; Mayer, M.; Vogel, H. ChemPhysChem 2003, 4, 268-275.

(15) Schmid, E. L.; Keller, T. A.; Dienes, Z.; Vogel, H. Anal. Chem. 1997, 69 1979-1985

(16) Sigal, G. B.; Bamdad, C.; Barberis, A.; Strominger, J.; Whitesides, G. M. Anal. Chem. 1996, 68, 490-497.

(17) Stora, T.; Hovius, R.; Dienes, Z.; Pachoud, M.; Vogel, H. Langmuir 1997, $13,5211-5214$.

(18) Salamon, Z.; Hazzard, J. T.; Tollin, G. Proc. Natl. Acad. Sci. U.S.A. 1993, 90, 6420-6423.

(19) Ataka, K.; Osawa, M. Langmuir 1998, 14, 951-959.

(20) Ataka, K.; Osawa, M. J. Electroanal. Chem. 1999, 460, 188-196.

(21) Ataka, K.; Yotsuyanagi, T.; Osawa, M. J. Phys. Chem. 1996, 100, 1066410672.

(22) Ataka, K.; Heberle, J. J. Am. Chem. Soc. 2003, 125, 4986-4987.

(23) Osawa, M.; Ataka, K.; Yoshii, K.; Yotsuyanagi, T. J. Electron Spectrosc. Relat. Phenom. 1993, 64-65, 371-379.

(24) Osawa, M. Surface-Enhanced Infrared Absorption Spectroscopy; In Handbook of Vibrational Spectroscopy; Chalmers, J. M., Griffiths, P. R., Eds.; Wiley: Chichester, U.K., 2002; pp 785-799. surface ${ }^{4,5,25-27}$ suffered from the lack of orientational control on the protein, which is mandatory for an unidirectional electron transfer.

$\mathrm{CcO}$ is the terminal protein of the respiratory chain that catalyzes the fission of molecular dioxygen to form water. The released energy contributes to the transfer of four electrons from four reduced cytochrome $c$ molecules, consumes four protons for the chemical conversion of each dioxygen molecule, and pumps four additional protons across the membrane. ${ }^{28}$ The net movement of charge contributes to the electrochemical gradient that is used to drive ATP synthesis. A team of heme and copper cofactors and a series of conserved amino acids coordinate the transfer of electrons, the pumping of protons, and the reduction of dioxygen. ${ }^{29-31}$ Though the structure of this respiratory enzyme has been determined to high resolution, ${ }^{32-34}$ the details of the intricate mechanism are far from being well-understood. Recent infrared experiments are elucidating the involvement of particular residues in the catalytic reaction sequence. ${ }^{35,36}$

\section{Materials and Methods}

Surface Modification. Figure 1 illustrates the various steps involved in the modification of the gold surface to attach the histidine-tagged protein via the affinity to Ni-NTA. The bare gold surface is exposed to a solution of $1 \mathrm{mg} / \mathrm{mL}$ dithiobis(succinimidylpropionate) (DTSP, Fluka) in DMSO. DTSP forms a monolayer spontaneously with the metal surface through covalent linkage to the sulfur group (Figure 1A). After monolayer formation, the surface is rinsed with pure DMSO several times and dried in a nitrogen stream. In the next step, the selfassembled monolayer (SAM) is immersed in an aqueous solution of $150 \mathrm{mM} N_{\alpha^{\prime}}, N_{\alpha^{\prime \prime}}$-bis(carboxymethyl)-L-lysine or amino-nitrilotriacetic acid (ANTA, Fluka) in $0.5 \mathrm{M} \mathrm{K}_{2} \mathrm{CO}_{3}$ buffer (pH 9.8). The amino group of ANTA reacts with DTSP to form a carboxamide linkage (Figure 1B).$^{37}$ Excess ANTA is removed by washing with ultrapure water. Finally, the NTA-terminated surface is incubated with $50 \mathrm{mM} \mathrm{NiSO}$ (Sigma) solution to ligate the $\mathrm{Ni}^{2+}$ ion via the three carboxylates and the tertiary amine of NTA.

After rinsing with water, $2 \mu \mathrm{M} \mathrm{CcO}$ dissolved in $0.1 \%$ dodecylmaltoside (DM, Anatrace, sol-grade 3105 ) and $50 \mathrm{mM}$ phosphate buffer was added to the $\mathrm{Ni}-\mathrm{NTA}$-coated Au surface. $\mathrm{CcO}$ with a $6 \times$ His-tag fused to the carboxy-terminus of subunit I was homologously expressed in $R$. sphaeroides and purified according to ref $38 . \mathrm{CcO}$ adsorbs to the $\mathrm{Ni}$-NTA moiety via the coordination of the nitrogen of two of the imidazole side chains of the $6 \times$ His-tag (Figure 1C). After formation of the $\mathrm{CcO}$ monolayer, excess $\mathrm{CcO}$ in solution is removed by rinsing the surface with buffer.

(25) Burgess, J. D.; Rhoten, M. C.; Hawkridge, F. H. J. Am. Chem. Soc. 1998 , $120,4488-4491$.

(26) Burgess, J. D.; Jones, V. W.; Porter, M. D.; Rhoten, M. C.; Hawkridge, F. M. Langmuir 1998, 14, 6628-6631.

(27) Haas, A. S.; Pilloud, D. L.; Reddy, K. S.; Babcock, G. T.; Moser, C. C.; Blasie, J. K.; Dutton, P. L. J. Phys. Chem. B 2001, 105, 11351-11362.

(28) Wikström, M. Biochim. Biophys. Acta 2004, 1655, 241-247.

(29) Babcock, G. T.; Ferguson-Miller, S. Chem. Rev. 1996, 96, 2889-2907.

(30) Karpefors, M.; Ädelroth, P.; Aagaard, A.; Sigurdson, H.; Svensson, E. M.; Brzezinski, P. Biochim. Biophys. Acta 1998, 1365, 159-169.

(31) Zaslavsky, D.; Gennis, R. B. Biochim. Biophys. Acta 2000, 1458, 164179.

(32) Tsukihara, T.; Aoyama, H.; Yamashita, E.; Tomizaki, T.; Yamaguchi, H. Shinzawa-Itoh, K.; Nakashima, R.; Yaono, R.; Yoshikawa, S. Science 1996 $272,1136-1144$.

(33) Iwata, S.; Ostermeier, C.; Ludwig, B.; Michel, H. Nature 1995, 376, 660669.

(34) Svensson-Ek, M.; Abramson, J.; Larsson, G.; Tornroth, S.; Brzezinski, P.; Iwata, S. J. Mol. Biol. 2002, 321, 329-339.

(35) Nyquist, R. M.; Heitbrink, D.; Bolwien, C.; Gennis, R. B.; Heberle, J. Proc. Natl. Acad. Sci. U.S.A 2003, 100, 8715-8720.

(36) Iwaki, M.; Puustinen, A.; Wikström, M.; Rich, P. R. Biochemistry 2003, $42,8809-8817$.

(37) Hermanson, G. T. Bioconjugate Techniques; Academic Press: San Diego, CA, 1996.

(38) Mitchell, D. M.; Gennis, R. B. FEBS Lett. 1995, 368, 148-150 
(A)

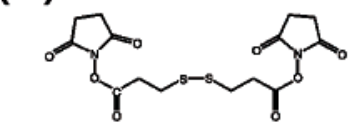

Dithiobis(succinimidylpropionate, DTSP

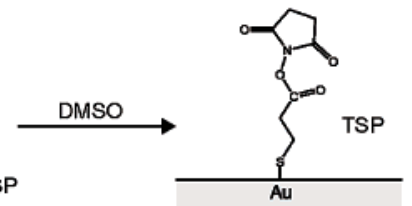

(B)
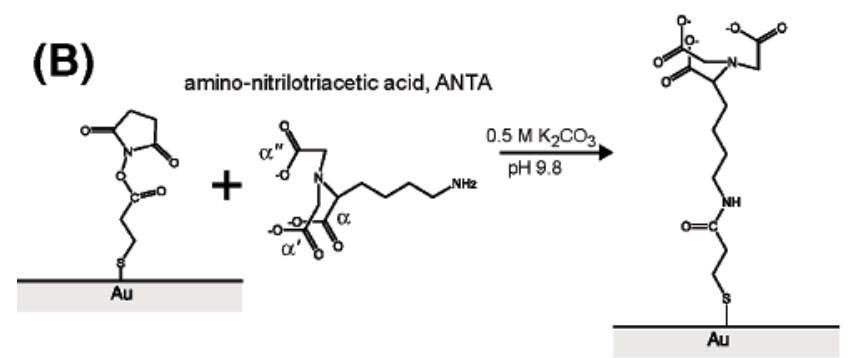

(C)
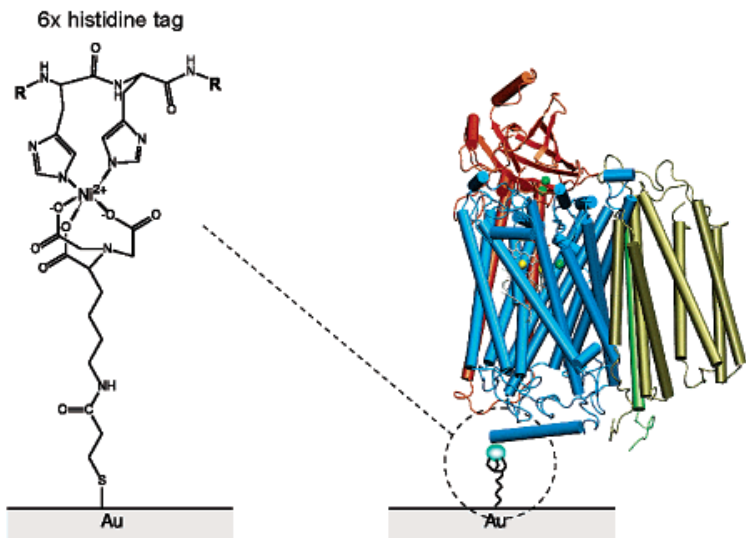

Figure 1. Reaction sequence of the surface modification process. (A) Selfassembly of the TSP monolayer on the bare Au surface by spontaneous splitting of the disulfide bond of DTSP. (B) Cross-linking of ANTA with the TSP monolayer. (C) Adsorption of cytochrome $c$ oxidase on the $\mathrm{Ni}-$ NTA modified Au surface via the His-tag at the C-terminus of subunit I. Two nitrogen atoms of the imidazole rings from two of the histidines of the His stretch are coordinating the $\mathrm{Ni}^{2+}$ ion. The coordinating histidines residues are not necessarily adjacent in the primary sequence as drawn in the figure, but the secondary structure of the His-tag determines which of the histidine residues serve as ligands to the $\mathrm{Ni}^{2+}$ ion.

At this stage, the surface is covered by a monolayer of detergentsolubilized $\mathrm{CcO}$. To retain full functional integrity, the solid supported membrane protein is incorporated into a lipid layer (Figure 2) as was shown in parallel by surface plasmon and electrochemical impedance spectroscopy. ${ }^{9}$ The surface-adsorbed $\mathrm{CcO}$ layer is mixed with detergentdestabilized lipid vesicles (liposomes) of di-myristoyl-phosphatidylcholine (DMPC from Sigma). Macroporous Bio-Beads (SM2 from Bio$\mathrm{Rad})$ are added to the mixture to remove the detergent. By these means, the lipid spontaneously assembles around the protein to form the protein-tethered bilayer lipid membrane. ${ }^{9}$

In Situ Electrochemical FT-IR Spectroscopy. The experimental setup and procedures for SEIRAS have already been described. ${ }^{22,39}$ Briefly, a thin gold film is formed on the flat surface of half-cylindershaped silicone prism by a chemical deposition technique. After electrochemical cleaning, the gold-coated prism is set into a glass cell. The IR beam from the interferometer of the FT-IR spectrometer (Bruker IFS 66v) is coupled into the prism at an incident angle of $60^{\circ}$. The reflected beam is recorded with a mercury cadmium telluride detector. Typically 100 to 640 scans were co-added for each spectrum. Neither baseline corrections nor any smoothing procedure has been applied to the data. Cyclic voltammetry has been performed with a potentiostat (Autolab PGSTAT 12, Metrohm, Filderstadt, Germany). Ag/AgCl in

(39) Ataka, K.; Heberle, J. J. Am. Chem. Soc. 2004, 126, 9445-9457.
$3 \mathrm{M} \mathrm{KCl}$ solution and platinum mesh have been used as a reference and a counter electrode, respectively. All potentials are quoted versus NHE $\left(+211.5 \mathrm{mV}\right.$ vs $\mathrm{Ag} / \mathrm{AgCl} / 3 \mathrm{M} \mathrm{KCl}$ at $\left.20^{\circ} \mathrm{C}\right)$.

Quantum Mechanical Calculations and Normal-Mode Analysis. The calculations have been performed with Gaussian $03^{40}$ on the IBM p690 cluster (Jülich multi-processor supercomputer, JUMP). Density functional theory (DFT) calculations were carried out with the B3LYP hybrid functional using the expanded basis set $6-31+G(d)$, where a set of polarization and diffuse functions for heavy atoms has been added suitable for large anions and electron lone pairs. For the uncharged thio(succinimidylpropionate) (TSP), solvation effects have not been considered, whereas for the strongly charged ANTA hydration effects have been taken into account by the SCRF Onsager model. For comparison with experimental spectra, scaling by a wavenumber linear function of the calculated frequencies is necessary. ${ }^{41}$ The parameters of the scaling function $v_{\text {scal }}=v_{\text {unscal }}\left(\mathrm{b}+m \cdot v_{\text {unscal }}\right)$ are obtained by fitting calculated data to the experimental data of ANTA, yielding $b=$ 1.34059 and $m=-0.00023$. These parameters have been verified by using reference data for $\mathrm{Na}-$ acetate.

\section{Results and Discussion}

Recombinant membrane proteins can be specifically tethered to a solid surface via the strong affinity of a genetically introduced His-tag for Ni-NTA. We will present the sequence of chemical modification steps that are required to build up a Ni-NTA modified gold surface. Finally, the oriented membrane protein monolayer of cytochrome $c$ oxidase is embedded into a lipid layer directly on the solid support. It is the great advantage of SEIRAS to in situ probe all of the modification steps of the gold surface. The catalytic activity of the surface-bound and reconstituted $\mathrm{CcO}$ is proven by cyclic voltammetry.

Self-Assembling the TSP Monolayer. The first step in the construction of a Ni-NTA layer is to employ the heterobifunctional cross-linker DTSP, which forms a covalent thio-adduct with the gold surface. For the in situ observation of this process by SEIRAS, a background spectrum was taken of the bare Au surface immersed in DMSO. Then, DTSP dissolved in DMSO was added, and IR spectra were recorded (Figure 3A) to monitor the self-assembling process of the TSP monolayer. After the addition of DTSP, three bands appear at 1809, 1782, and 1739 $\mathrm{cm}^{-1}$, which increase in intensity over time. The frequency of these bands corresponds to the $\mathrm{C}=\mathrm{O}$ stretching modes of the succinimidyl ester of TSP. On the basis of DFT calculations (Table 1), we assign the bands at 1739 and $1782 \mathrm{~cm}^{-1}$ to the asymmetric and symmetric stretching, respectively, of two $\mathrm{C}=$ $\mathrm{O}$ groups of the succinimidyl ring (see Figure 1A). The band at $1809 \mathrm{~cm}^{-1}$ is attributed to the $\mathrm{C}=\mathrm{O}$ stretching vibration of the ester group of TSP.

The binding kinetics is revealed by plotting the intensity of the strongest band at $1739 \mathrm{~cm}^{-1}$ against adsorption time (Figure

(40) Frisch, M. J.; Trucks, G. W.; Schlegel, H. B.; Scuseria, G. E.; Robb, M. A.; Cheeseman, J. R.; Montgomery, J. A., Jr.; Vreven, T.; Kudin, K. N.; Burant, J. C.; Millam, J. M.; Iyengar, S. S.; Tomasi, J.; Barone, V.; Mennucci, B.; Cossi, M.; Scalmani, G.; Rega, N.; Petersson, G. A.; Nakatsuji, H.; Hada, M.; Ehara, M.; Toyota, K.; Fukuda, R.; Hasegawa, J.; Ishida, M.; Nakajima, T.; Honda, Y.; Kitao, O.; Nakai, H.; Klene, M. Li, X.; Knox, J. E.; Hratchian, H. P.; Cross, J. B.; Adamo, C.; Jaramillo, J.; Gomperts, R.; Stratmann, R. E.; Yazyev, O.; Austin, A. J.; Cammi, R.; Pomelli, C.; Ochterski, J. W.; Ayala, P. Y.; Morokuma, K.; Voth, G. A.; Salvador, P.; Dannenberg, J. J.; Zakrzewski, V. G.; Dapprich, S.; Daniels, A. D.; Strain, M. C.; Farkas, O.; Malick, D. K.; Rabuck, A. D. Raghavachari, K.; Foresman, J. B.; Ortiz, J. V.; Cui, Q.; Baboul, A. G.; Clifford, S.; Cioslowski, J.; Stefanov, B. B.; Liu, G.; Liashenko, A.; Piskorz, P.; Komaromi, I.; Martin, R. L.; Fox, D. J.; Keith, T.; Al-Laham, M. A.;

Peng, C. Y.; Nanayakkara, A.; Challacombe, M.; Gill, P. M. W.; Johnson,

B.; Chen, W.; Wong, M. W.; Gonzalez, C.; Pople, J. A. Gaussian 03 revision B.03; Gaussian, Inc.: Pittsburgh, PA, 2003.

(41) Magalhaes, A. L.; Pinto, A. S. S. Theor. Chem. Acc. 2003, 110, 70-78. 


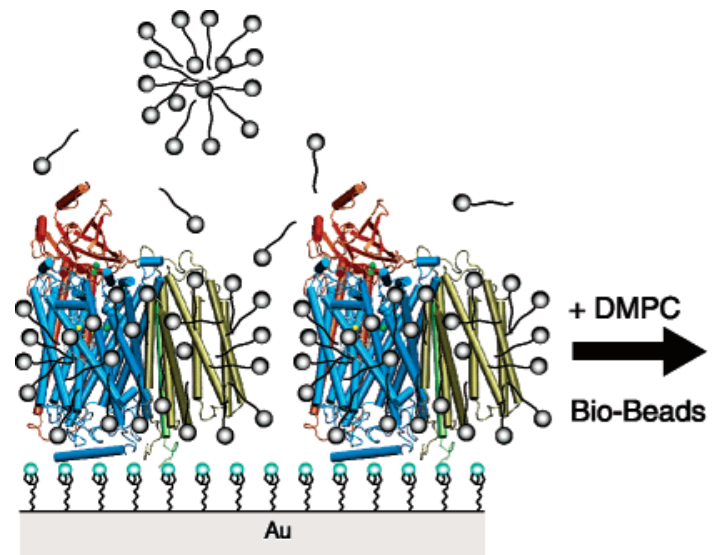

dodecylmaltoside (DM)

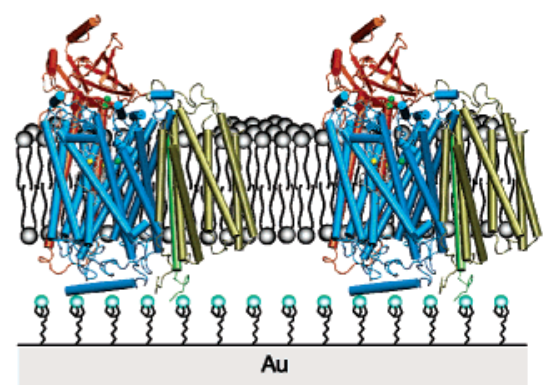

dimyristoylphosphatidylcholine (DMPC)

Figure 2. Schematic representation of the reconstitution of surface-tethered cytochrome $c$ oxidase into a lipid bilayer. The surface-adsorbed cytochrome $c$ oxidase via the affinity of the His-tag to the Ni-NTA surface (see Figure 1) is surrounded by the detergent dodecylmaltoside (left). After reaching maximum surface coverage, the protein is exposed to detergent-destabilized lipid vesicles (DMPC), and microporous Bio-Beads are added. The retreat of the detergent molecules by the beads drives the lipids to form a layer around the membrane protein (right).
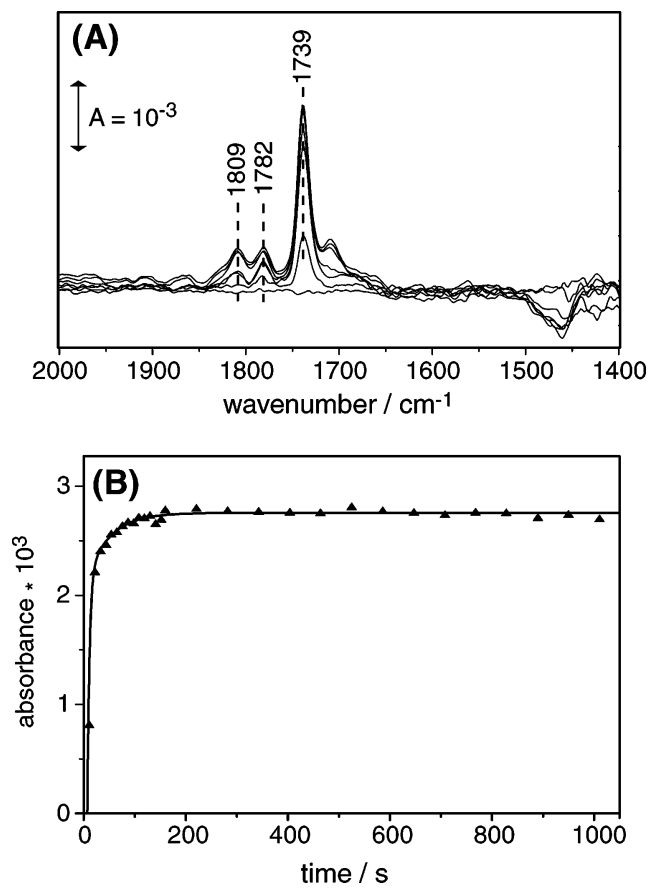

Figure 3. (A) SEIRA spectra of the binding of DTSP to the Au surface. The displayed spectra are taken at $0,10,20,30,60,120$, and $200 \mathrm{~s}$ after the addition of DTSP. The reference spectrum is taken from the solvent DMSO in contact with the bare Au surface. (B) Adsorption kinetics of DTSP to the bare Au surface. The peak height of the strongest band at $1739 \mathrm{~cm}^{-1}$ is plotted against the adsorption time.

3B). The intensity of the band is saturated at about $200 \mathrm{~s}$, suggesting that the self-assembly of the TSP layer is completed within this short time range.

Coupling of TSP to ANTA. The surface-bound succinimidylester moiety of TSP is employed to react with the primary amine of ANTA (cf. Figure 1B). This reaction yields an NTA surface dedicated to finally ligate a $\mathrm{Ni}^{2+}$ ion. After formation of the TSP monolayer on gold, the sample is rinsed with DMSO and dried under a stream of nitrogen. The TSP monolayer is covered by an aqueous solution of $0.5 \mathrm{M} \mathrm{K}_{2} \mathrm{CO}_{3}$ buffer $(\mathrm{pH}$ 9.8), and a reference IR spectrum is taken. Then, an aqueous solution of ANTA is applied, and a series of IR spectra is recorded during the cross-linking process (Figure 4). The negative bands in the difference spectra indicate the vibrations of the reactant at the surface (TSP), while positive bands represent the product species (NTA). Three negative features are observed at $1808,1781,1733 \mathrm{~cm}^{-1}$. Since all of these bands have been assigned to the succinimidylester vibrations of TSP, this provides direct evidence for the reaction of the succinimidylester. Concomitant with the appearance of the negative band of DTSP, two intense bands appear at 1658 and $1571 \mathrm{~cm}^{-1}$. These bands originally exist in neither the bulk spectra of ANTA nor DTSP (data not shown). The bands are assigned to the amide I $(\mathrm{C}=\mathrm{O}$ stretching vibration $)$ and the amide $\mathrm{II}$ mode $(\mathrm{C}=\mathrm{N}$ stretch coupled to the $\mathrm{N}-\mathrm{H}$ bending vibration) of the carboxamide $(-\mathrm{CONH}-)$ linkage, ${ }^{42}$ respectively. The appearance of these bands provides unequivocal evidence for the presence of the cross-link between ANTA and TSP.

The bands of the asymmetric carboxylate vibrations are also expected at around $1600 \mathrm{~cm}^{-1} .{ }^{42}$ These bands could not be clearly resolved due to the overlap with the amide I band of the carboxamide. The normal mode calculations on the deprotonated ANTA (Table 1 and Figure 1B), however, show that the broad band feature around $1600 \mathrm{~cm}^{-1}$ (Figure 4) involves the asymmetric vibrations of the terminal carboxylates of ANTA.

The bands at around $1400 \mathrm{~cm}^{-1}$ region are assigned to the corresponding symmetric stretching modes of the three carboxylate groups of NTA. Accordingly, three peaks are resolved at 1440,1413 , and $1402 \mathrm{~cm}^{-1}$. The DFT calculations (Table 1) reveal that multiple symmetric $\mathrm{COO}^{-}$stretching vibrations appear in the range of $1424-1380 \mathrm{~cm}^{-1}$ for each of the three carboxylates. However, the detailed assignment of the symmetric carboxylate vibrations is hampered by the strong coupling to the $\mathrm{C}-\mathrm{H}$ in-plane bending and the $\mathrm{C}-\mathrm{N}$ stretching modes of the molecule.

It should be noted that the occurrence of the carboxylate bands is suppressed by the addition of a 1:4 mixture of amino-ethanol and ANTA (data not shown). This result suggests that aminoethanol reacts with TSP and, thus, prevents the coupling reaction

(42) Venyaminov, S. Y.; Kalnin, N. N. Biopolymers 1990, 30, 1259-1271. 
Table 1. Comparison of the Experimental with the Calculated IR Frequencies of the Carbonyl Stretching Vibrations of Thiobis(succinimidylpropionate) (TSP, see Figure 3 for the data) and of the Carboxylate Vibrations of Amino-Nitrilotriacetic Acid (ANTA, see Figure 4 for the data)

\begin{tabular}{|c|c|c|c|}
\hline$v_{\text {expit }}\left[\mathrm{cm}^{-1}\right]$ & $v_{\text {scal }}\left[\mathrm{cm}^{-1}\right]$ & $\nu_{\text {unscal }}\left[\mathrm{cm}^{-1}\right]$ & type of vibrations \\
\hline & & TSP & \\
\hline 1809 & 1812 & 1907 & $v \mathrm{C}=\mathrm{O}$ succinimidyl ring $+v \mathrm{C}=\mathrm{O}$ ester \\
\hline 1782 & 1784 & 1878 & $v \mathrm{C}=\mathrm{O}$ succinimidyl ring $+v \mathrm{C}=\mathrm{O}$ ester \\
\hline \multirow[t]{2}{*}{1739} & 1740 & 1832 & $v \mathrm{C}=\mathrm{O}$ succinimidyl ring \\
\hline & & ANTA & \\
\hline overlapped by & 1575 & 1630 & $v_{\text {asym }} \mathrm{COO}^{-}(\alpha)+\delta \mathrm{C}-\mathrm{H}$ \\
\hline amide I and II & 1564 & 1612 & $v_{\text {asym }} \mathrm{COO}^{-}\left(\alpha^{\prime \prime}\right)+\delta \mathrm{C}-\mathrm{H}$ \\
\hline \multirow[t]{3}{*}{$(1658-1571)$} & 1557 & 1600 & $v_{\text {asym }} \mathrm{COO}^{-}\left(\alpha^{\prime}\right)+\delta \mathrm{C}-\mathrm{H}$ \\
\hline & 1424 & 1397 & $v_{\mathrm{sym}} \mathrm{COO}^{-}(\alpha)+\delta \mathrm{C}-\mathrm{H}$ \\
\hline & 1412 & 1382 & $v_{\mathrm{sym}} \mathrm{COO}^{-}\left(\alpha+\alpha^{\prime \prime}\right)+\delta \mathrm{C}-\mathrm{H}$ \\
\hline \multirow{6}{*}{$\begin{array}{l}1440 \\
1413 \\
1402\end{array}$} & 1405 & 1371 & $v_{\mathrm{sym}} \mathrm{COO}^{-}(\alpha)+\delta \mathrm{C}-\mathrm{H}+v \mathrm{~N}-\mathrm{C}$ \\
\hline & 1391 & 1350 & $v_{\mathrm{sym}} \mathrm{COO}^{-}\left(\alpha+\alpha^{\prime}\right)+\delta \mathrm{C}-\mathrm{H}$ \\
\hline & 1388 & & \\
\hline & 1388 & 1346 & $v_{\mathrm{sym}} \mathrm{COO}^{-}\left(\alpha^{\prime \prime}\right)+v \mathrm{~N}-\mathrm{C}+\delta \mathrm{C}-\mathrm{H}$ \\
\hline & 1383 & 1339 & $v_{\text {sym }} \mathrm{COO}^{-}\left(\alpha+\alpha^{\prime}+\alpha^{\prime \prime}\right)+\delta \mathrm{C}-\mathrm{H}$ \\
\hline & 1380 & 1335 & $v_{\text {sym }} \mathrm{COO}^{-}\left(\alpha^{\prime}+\alpha^{\prime \prime}\right)+v \mathrm{~N}-\mathrm{C}+\delta \mathrm{C}-\mathrm{H}$ \\
\hline
\end{tabular}

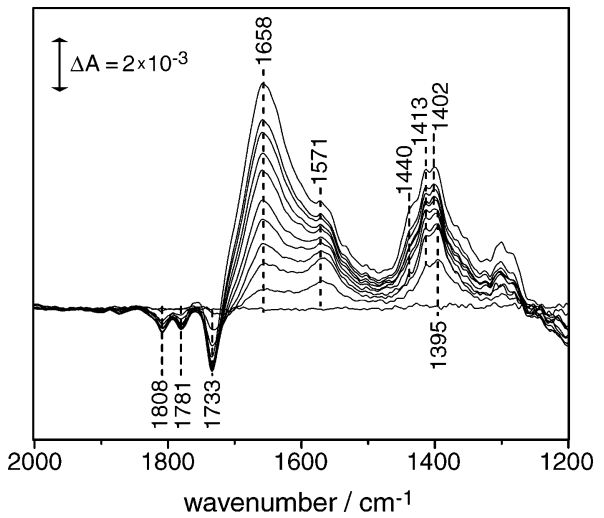

Figure 4. Surface-enhanced IR difference absorption (SEIDA) spectra of the coupling process of ANTA with the surface-bound TSP monolayer recorded at 10,20 , and $30 \mathrm{~s}$, and $1,2,5,10,15,30,60$, and $85 \mathrm{~min}$ after the start of the reaction. The reference spectrum is taken from the TSPmodified Au surface. The negative bands correspond to the vibrations of the molecules which are consumed at the surface (reactant), while the positive bands arise from those formed at the surface (product).

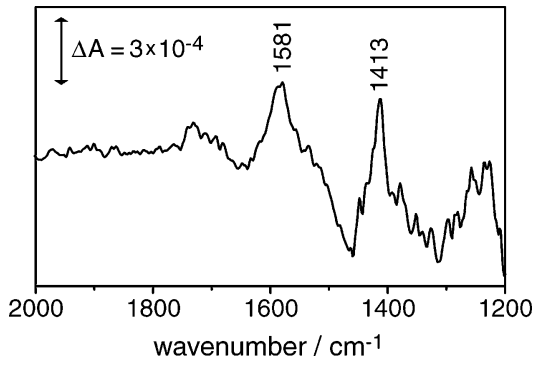

Figure 5. Vibrational changes of NTA induced by complexation of $\mathrm{Ni}^{2+}$. The reference spectrum has been taken in the presence of $50 \mathrm{mM} \mathrm{K}_{2} \mathrm{SO}_{4}$, and the difference spectrum has been recorded $15 \mathrm{~min}$ after addition of 50 $\mathrm{mM} \mathrm{NiSO}_{4}$. The $\mathrm{pH}$ has been kept constant at 4.8 .

with ANTA. Hence, this experiment supports our conclusion, which assigns the bands around $1400 \mathrm{~cm}^{-1}$ to the symmetric carboxylate vibrations of the NTA layer.

Complexation of $\mathbf{N i}^{2+}$ by NTA. Figure 5 depicts the difference spectrum of surface-bound NTA before and after the addition of $50 \mathrm{mM} \mathrm{NiSO}$. Complexation of $\mathrm{Ni}^{2+}$ leads to only small spectral changes. However, two bands at 1581 and 1413 $\mathrm{cm}^{-1}$ are apparent in the IR spectrum. These bands are assigned to the asymmetric and the symmetric stretching mode of the terminal carboxylate groups of NTA that get deprotonated during complexation of the $\mathrm{Ni}^{2+}$ ion.

The experiments thus far demonstrate the great potential of the SEIRAS methodology. Monolayers of these small molecules, TSP and NTA, can be hardly detected by common surfacesensitive methods such as surface plasmon resonance (SPR) or quartz crystal microbalance (QCM). ${ }^{9}$ Hence, SEIRAS is the only means to follow self-assembly and coupling in real time and, moreover, to obtain structural information about such molecules on the surface.

Adsorption of Detergent-Solubilized CcO to the Ni-NTA Layer. After activation of the gold surface, $\mathrm{CcO}$ is bound through the affinity of the genetically introduced His-tag for the Ni-NTA layer (Figure 1C). To monitor the adsorption of $\mathrm{CcO}$ by SEIRAS, a reference spectrum is taken in the presence of buffer solution (including $0.1 \%$ dodecyl-maltoside as detergent). Then, detergent-solubilized $\mathrm{CcO}$ was added to yield a final concentration of $2 \mu \mathrm{M}$, and the IR measurements were started. As shown in Figure 6A, bands appear at 1658, 1550, 1436 , and $1290 \mathrm{~cm}^{-1}$. The former two bands are readily assigned to the amide I and the amide II modes of the protein backbone vibrations of $\mathrm{CcO}$, respectively. ${ }^{43}$ The peak position of the amide I band is characteristic for a predominantly $\alpha$-helical protein such as $\mathrm{CcO}$. The increase of the band intensities in the course of incubation reflects the accumulation of $\mathrm{CcO}$ onto the $\mathrm{Ni}-$ NTA surface. The contribution of $\mathrm{CcO}$ from the bulk phase is negligible since its signal is hardly detectable at this concentration $(2 \mu \mathrm{M})$. Moreover, the observed IR bands (Figure 6A) arise exclusively from surface-bound $\mathrm{CcO}$ molecules because the effective distance of the SEIRAS enhancement is less than 10 $\mathrm{nm} .{ }^{24}$ In addition, the specific and reversible attachment of the $\mathrm{CcO}$ to the Ni-NTA layer has been demonstrated by SPR and QCM. ${ }^{9}$

The assignment of the bands at 1436 and $1290 \mathrm{~cm}^{-1}$ is unclear. These bands do not arise from $\mathrm{CcO}$ since they appear at the same position irrespective of the nature of the protein used (data not shown). Neither of the detergent dodecylmaltoside exhibits such vibrational bands. Therefore, we suggest that they originate from the $\mathrm{Ni}-\mathrm{NTA}$ layer, which may experience a conformational change due to the adsorption of $\mathrm{CcO}$. Conse-

(43) Krimm, S.; Bandekar, J. Adv. Protein Chem. 1986, 38, 181-364. 

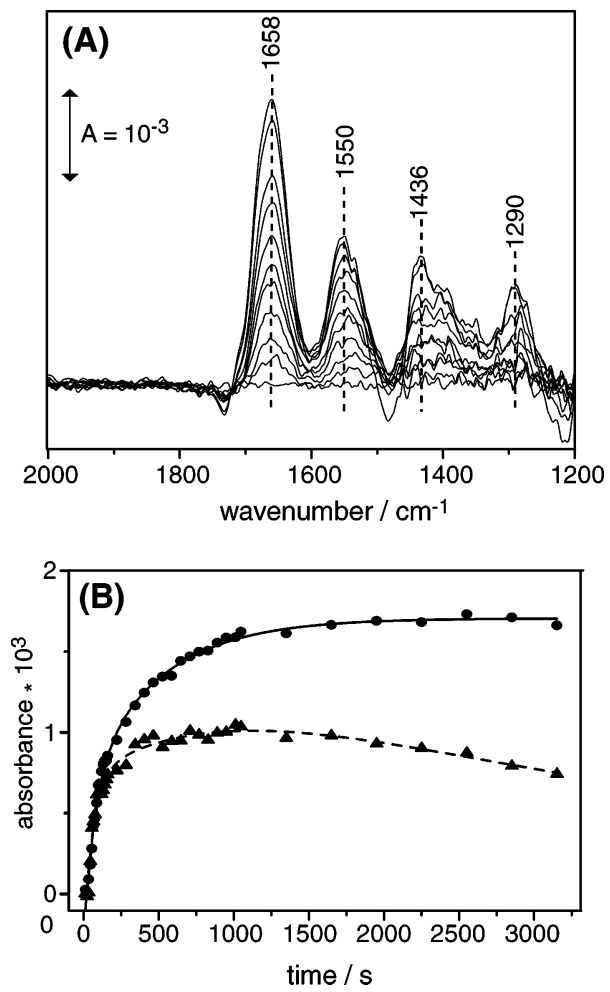

Figure 6. (A) SEIRA spectra of cytochrome $c$ oxidase adsorbed to the $\mathrm{Ni}-\mathrm{NTA}$ modified Au surface via the affinity for the genetically introduced His-tag. The rising bands indicate the binding of the protein to the surface and are discussed in the text. (B) Adsorption kinetics of $\mathrm{CcO}$ on the $\mathrm{Ni}-$ NTA SAM/Au surface. The peak height of the amide II band at $1550 \mathrm{~cm}^{-1}$ is plotted versus adsorption time. The filled circles represent the first adsorption of $\mathrm{CcO}$, while the triangles represent the adsorption process of $\mathrm{CcO}$ after removing the previous $\mathrm{CcO}$ layer by imidazole.

quently, the band at $1436 \mathrm{~cm}^{-1}$ can be assigned to the symmetric stretching vibration of the carboxylate group of NTA which complexes the $\mathrm{Ni}^{2+}$ ion. As soon as the His-tag of $\mathrm{CcO}$ ligates the $\mathrm{Ni}^{2+}$ ion, the interaction with the carboxylates of NTA may be disturbed and the corresponding vibrational bands may be shifted, finally.

The kinetics of adsorption of His-tagged $\mathrm{CcO}$ to the $\mathrm{Ni}-$ NTA surface is depicted in Figure 6B, where the intensity of the amide II band (filled circles) is plotted versus the adsorption time. The continuous line represents an exponential fit to the data, which yields a time constant of $\tau=213 \mathrm{~s}$ for the adsorption kinetics. The intensity becomes saturated at about $2000 \mathrm{~s}$.

Desorption of Bound $\mathrm{CcO}$ by Imidazole. To exclude nonspecific adsorption of $\mathrm{CcO}$ to the $\mathrm{Ni}-\mathrm{NTA}$ surface, we added excess imidazole to replace those $\mathrm{CcO}$ molecules that are specifically bound via the His-tag. This strategy is commonly used in metal-chelate affinity chromatography to elute the protein from the column. Figure 7A shows the difference spectra of $\mathrm{CcO}$ bound to the Ni-NTA surface after the addition of 230 $\mathrm{mM}$ imidazole. The depletion bands at $1659 \mathrm{~cm}^{-1}$ (amide I) and $1554 \mathrm{~cm}^{-1}$ (amide II) clearly indicate the desorption of $\mathrm{CcO}$. The comparison of the band intensities of the adsorption process (Figure 6A) and the desorption process (Figure 7A) reveals that almost all $\mathrm{CcO}$ molecules are detached from $\mathrm{Ni}-\mathrm{NTA}$ by adding imidazole. This suggests that the binding of $\mathrm{CcO}$ to the $\mathrm{Ni}-$ NTA layer through the His-tag is very specific. Vibrational
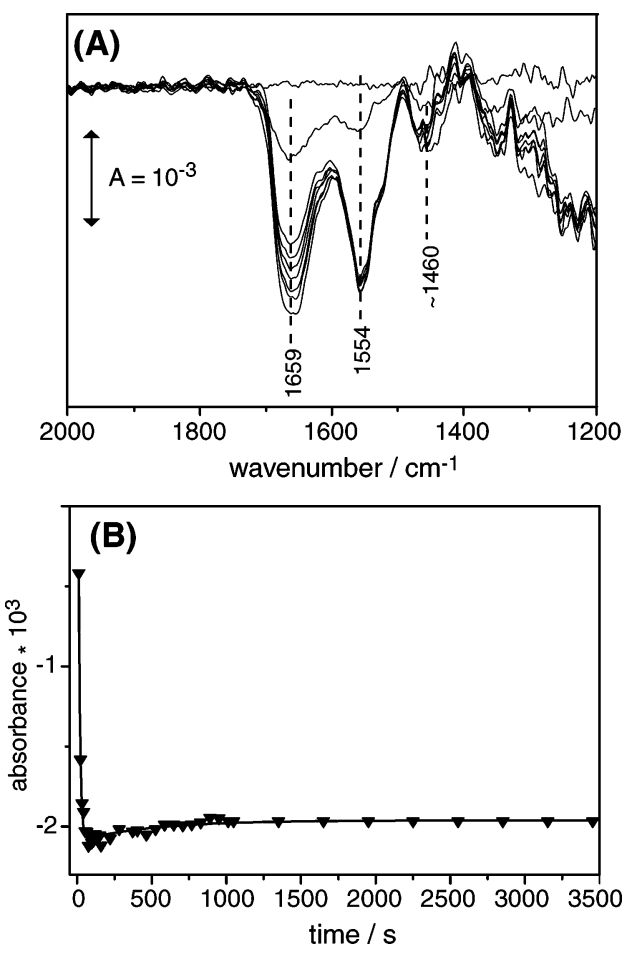

Figure 7. (A) SEIDA spectra of the desorption of $\mathrm{CcO}$ from the $\mathrm{Ni}-$ NTA surface by incubation with an aqueous solution of $230 \mathrm{mM}$ imidazole. The reference spectrum is taken from the surface covered by $\mathrm{CcO}$. (B) Desorption kinetics of $\mathrm{CcO}$ followed by the peak at $1550 \mathrm{~cm}^{-1}$ (amide II).

bands of molecular imidazole are not detectable because they cancel in the difference experiment with those of the histidine side chain.

Figure 7B shows the intensity decrease of the amide II band of $\mathrm{CcO}$ by the time of desorption. It is clear that the desorption kinetics $\left(\tau_{\text {desorption }}=10 \mathrm{~s}\right)$ is much faster than the adsorption kinetics $\left(\tau_{\text {adsorption }}=213 \mathrm{~s}\right.$, Figure $6 \mathrm{~B}$ ).

It is important to note that after imidazole has been removed by rinsing with buffer solution, $\mathrm{CcO}$ can again be adsorbed to the Ni-NTA surface. The binding kinetics of $\mathrm{CcO}$ (triangles in Figure 6B) on such a regenerated $\mathrm{Ni}-\mathrm{NTA}$ modified gold surface shows very similar binding kinetics albeit with a reduced final surface coverage (about $60 \%$ as compared to the initial adsorption experiment, see filled circles in Figure 6B). Although the efficacy of binding is apparently reduced, it is nevertheless demonstrated that the His-tagged membrane protein can be repeatedly adsorbed to the $\mathrm{Ni}-\mathrm{NTA}$ SAM surface. The decrease in the binding curve at long incubation times indicates some loss of protein $(<20 \%$ after $1 \mathrm{~h})$. These results are fully in accordance with SPR and QCM data. ${ }^{9}$

Reconstitution of Surface-Tethered CcO into a Lipid Layer. The binding procedure of $\mathrm{CcO}$ to the $\mathrm{Ni}-\mathrm{NTA}$ modified $\mathrm{Au}$ surface involves the use of detergent to solubilize the membrane protein. For embedding the protein into a membranelike environment, we devised a new strategy for functional incorporation of the surface-tethered membrane protein into a lipid layer directly on the solid surface by adding Bio-Beads as a substitute for in situ dialysis used in our other study. ${ }^{9}$

The surface-tethered $\mathrm{CcO}$ was exposed to $1 \mathrm{~mL}$ of buffer solution (50 mM phosphate, $\mathrm{pH}$ 8.0) of $1 \mathrm{mg}$ DMPC dissolved in $0.1 \%$ dodecylmaltoside (DM). A spectrum was measured under these conditions and stored as reference. Then, $50 \mathrm{mg}$ of 


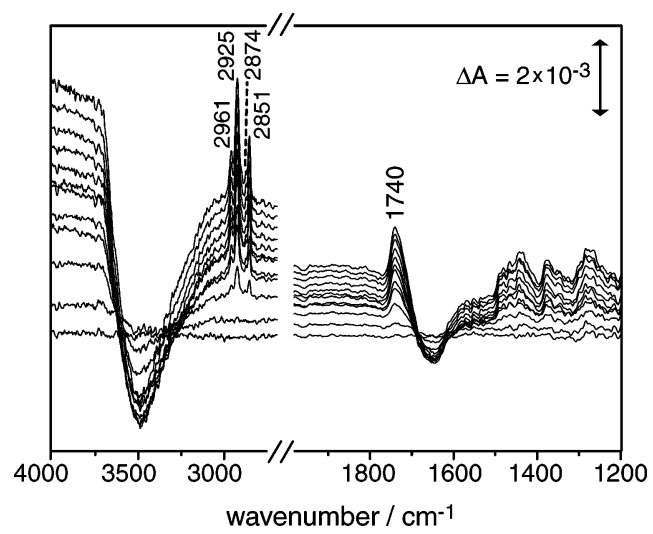

Figure 8. SEIDA spectra of the reconstitution process of $\mathrm{CcO}$ into a lipid layer of DMPC. The reference spectrum is taken from surface-bound $\mathrm{CcO}$ solubilized in the detergent dodecylmaltoside. Detergent removal and the formation of the lipid layer are initiated by the addition of Bio-Beads to the solution. Spectra have been recorded at an interval of $5 \mathrm{~min}$. The positive bands that appear in the difference spectra indicate the presence of DMPC along the surface. Saturation of the adsorption kinetics occurs about $1 \mathrm{~h}$ after the addition of Bio-Beads. The baseline drift in the spectra results from instabilities over the very long observation time $(1 \mathrm{~h})$.

Bio-Beads was added to the solution, and sample spectra were recorded over time. The incorporation of DMPC is clearly indicated by the appearance of vibrational bands in the region between 2800 and $3000 \mathrm{~cm}^{-1}$ and at $1740 \mathrm{~cm}^{-1}$ (Figure 8). The former bands can be readily assigned to the $\mathrm{C}-\mathrm{H}$ stretching modes of the two alkyl chains of DMPC (symmetrical and asymmetrical $\mathrm{CH}_{3}$ and $\mathrm{CH}_{2}$ modes), while the latter band is due to the $\mathrm{C}=\mathrm{O}$ stretching mode of its ester headgroup. ${ }^{44}$ The positive differential absorbance in the $\mathrm{C}-\mathrm{H}$ stretching region indicates that the number of $\mathrm{C}-\mathrm{H}$ groups increases when the lipid DMPC replaces the detergent DM. This plausible suggestion is well supported by the appearance of the $\mathrm{C}=\mathrm{O}$ stretching vibration, which is present in DMPC but absent in DM.

It is important to note that we did not observe any vibrational changes of the adsorbed proteins in this dialysis experiment. This suggests that the protein is steadily bound to the surface and does not dissociate from the Ni-NTA surface during the course of exchange from detergent to lipid.

IR spectroscopy, however, is not designed to prove bilayer formation. Electrochemical impedance spectroscopy (EIS) measurements of the reconstitution revealed a considerable decrease of the capacitance and an increase of the resistance which is compatible with the formation of a lipid bilayer encompassing a high protein concentration (for details, see ref 9). More significantly, EIS also revealed a fully reversible decrease of the resistance in the presence of cytochrome $c$, which is considered due to active proton transport, feasible only across an intact lipid bilayer. ${ }^{9}$

Probing the Functionality of the Surface-Tethered CcO. Finally, it has been checked whether electron transfer takes place in this biomimetic system in a comparable manner to the physiological situation. Electron transfer is probed by cyclic voltammetry. It is advantageous that the His-tag on the C-terminus of SU I orients the $\mathrm{CcO}$ to have the binding site for the natural electron donor cyt $c$ freely accessible to the aqueous

(44) Lewis, R. N. A. H.; McElhaney, R. N. Vibrational Spectroscopy Spectroscopy of Lipids; In Handbook of Vibrational Spectroscopy; Chalmers, J. M., Griffiths, P. R., Eds.; Wiley: Chichester, U.K., 2002; pp 34653480 .

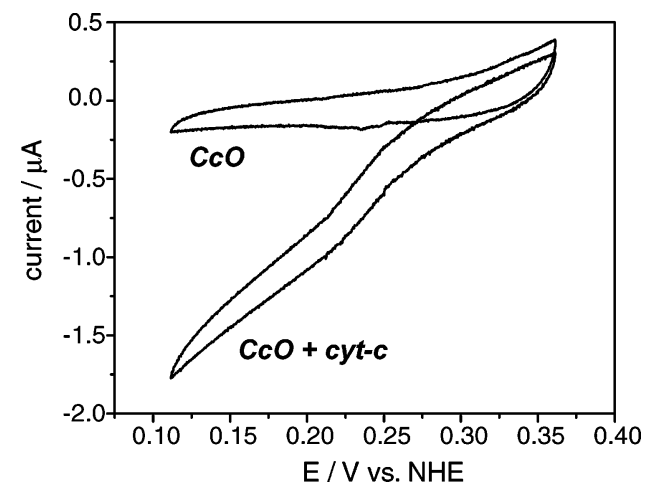

Figure 9. Cyclic voltammogram of the surface-tethered and membranereconstituted $\mathrm{CcO}$ in complex with the natural electron donor cyt $c$ as compared to that of $\mathrm{CcO}$ alone. Scan rate is $2 \mathrm{mV} / \mathrm{s}$.

bulk phase. Therefore, cyt $c$ (from horse heart) is added to a final concentration of $2 \mu \mathrm{M}$. The ionic strength of the aqueous medium was set to $75 \mathrm{mM} \mathrm{KCl}(\mathrm{pH} \mathrm{8.0)}$ ) where the complex of horse heart cyt $c$ and bacterial $\mathrm{CcO}$ exhibits the most efficient electron-transfer kinetics. ${ }^{45}$

The cyclic voltammogram (Figure 9) demonstrates the reversible redox reaction between cyt $c$ and the surface-tethered $\mathrm{CcO}$. The midpoint potential is $244.1 \mathrm{mV}$ vs NHE as determined by a faster scan rate of $50 \mathrm{mV} / \mathrm{s}$ (data not shown). This value is very close to that determined by Haas et al. $(225 \mathrm{mV}$ vs NHE) ${ }^{27}$ In the absence of the electron donor cyt $c$ (lower trace in Figure 9), $\mathrm{CcO}$ exhibits only a capacitive current of the dielectric layer, but the current indicating electrocatalytic activity is not observed. This suggests that $\mathrm{CcO}$ is not electrically coupled to the electrode, and thus direct electron transfer does not take place. However, as cyt $c$ is added, a reductive current starts to flow at a potential lower than $270 \mathrm{mV}$. At even lower potential, cyt $c$ is electrochemically reduced by the electrode and thus readily donates electrons to $\mathrm{CcO}$. The donation of electron initiates the oxygen reduction performed by $\mathrm{CcO}$. This appears as a reductive current in the negative potential region. After reaching a potential of $-111 \mathrm{mV}$, the sweep direction is reversed and the current decreases again. At a potential above $270 \mathrm{mV}$, the current in the two cyclic voltammogram starts to merge. Since this is the potential range where cyt $c$ is in the oxidized form, the electron donation from cyt $c$ to $\mathrm{CcO}$ is suppressed above $270 \mathrm{mV}$. The catalytic activity of the cyt $c / \mathrm{CcO}$ complex is drastically reduced when the ionic strength of the aqueous solution is changed (data not shown), demonstrating the specificity of cyt $c$ binding.

These results are supported by EIS, which probes active proton transport catalyzed by dioxygen reduction. ${ }^{9}$ Proton transport was shown to be reversible, suppressed by removing cytochrome $c$, and specifically inhibited by cyanide. Therefore, the assumption seems justified that the activity of the protein is preserved when it is immobilized on the surface.

The same enzyme, however, with the His-tag engineered into the $\mathrm{C}$-terminus of subunit II that orients the $\mathrm{CcO}$ to have the cyt $c$ binding on the inner side of the dielectric layer and hence not accessible to the aqueous bulk phase, was also immobilized and reconstituted according to the same protocol. It was then investigated by surface-enhanced resonance-Raman spectroscopy. This technique is extremely sensitive to the structure and

(45) Wang, K.; Geren, L.; Zhen, Y.; Ma, L.; Ferguson-Miller, S.; Durham, B.; Millett, F. Biochemistry 2002, 41, 2298-2304. 
functionality of the heme binding sites. Redox states of the fully oxidized and fully reduced enzyme could thus be detected, and direct electron transfer could be shown to take place from the metal electrode to the protein, ${ }^{46}$ in this case with no interaction with cytochrome $c$. All of these results provide immediate evidence for the orientation-dependent functionality of the reconstituted and surface-tethered $\mathrm{CcO}$.

\section{Conclusions}

In this work, we are pursuing a novel strategy for the reconstitution of a membrane protein monolayer in a lipid layer on a solid support. Each step of the reconstitution process is monitored by SEIRAS. These steps are: (1) Self-assembly of the active ester TSP on the metal support, (2) formation of the $\mathrm{Ni}-\mathrm{NTA}$ layer by cross-linking of the active ester with ANTA and complexation with $\mathrm{Ni}^{2+}$, (3) adsorption of the His-tagged protein on the $\mathrm{Ni}-\mathrm{NTA}$ layer, and (4) integration of the protein monolayer into the lipid layer. The experimentally observed vibrational frequencies of the various steps have been unambiguously assigned to normal modes by quantum mechanical calculations.

Cross-linking of NTA via a thio-alkane chain to the metal surface (steps 1 and 2) employs only commercially available products, which makes it a simple and cheap approach. Since the introduction of a His-tag becomes nowadays a routine task, surface-tethering via the affinity for $\mathrm{Ni}-\mathrm{NTA}$ represents (step 3) a very versatile technique applicable to virtually any recombinant protein. Finally, the reconstitution of the surfacetethered protein into a lipid layer (step 4) leads to enhanced stability of the protein mimicking the natural environment of a biological membrane.

(46) Friedrich, M.; Giess, F.; Naumann, R.; Knoll, W.; Ataka, K.; Heberle, J.; Hrabakova, J.; Murgida, D.; Hildebrandt, P. Chem. Commun. 2004, 21 , $2376-2377$.
It is evident that the specific binding of the protein via the affinity tag orients the bound proteins in a homogeneous manner. This simplifies or even enables studies on vectorial ion and electron transfer of membrane proteins which require almost perfect orientation. Moreover, the His-tag can be attached to the opposite side of the membrane protein surface, which elegantly reverses the orientation of the protein layer with respect to the electrode.

The presented methodology will be extended to investigations of the reaction mechanism of membrane proteins. An extremely powerful technique for these studies is IR difference spectroscopy, which selectively probes the vibrational changes associated with functionality. ${ }^{47,48}$ Proper orientation of the protein monolayer is mandatory for time-resolved studies of the dynamics of those molecular machines that act as rectifiers, like those involved in vectorial electron transfer across the membrane. Such studies will be accomplished by surface-enhanced IR difference spectroscopy and are currently underway. The presented methodology is applicable to those membrane proteins that are gated by a membrane potential and, thus, opens a new avenue to study the mechanism of these medically and pharmaceutically very important class of proteins on the atomic level.

Acknowledgment. We are grateful to Profs. Peter Brzezinski (Stockholm) and Robert B. Gennis (Urbana-Champaign) for providing the $R$. sphaeroides strains with His-tagged cytochrome $c$ oxidase. We also acknowledge Prof. G. Büldt for continuous generous support. S.H.P. thanks A. Pohlmeier for helpful discussions. This work has been supported by a grant from the Volkswagen foundation ("Intra- und intermolekulare Elektronenübertragung") to J.H.

JA045951H

(47) Vogel, R.; Siebert, F. Curr. Opin. Chem. Biol. 2000, 4, 518-523 (48) Nyquist, R. M.; Ataka, K.; Heberle, J. ChemBioChem 2004, 5, 431-436. 